\title{
Novas perspectivas e
}

\section{conceitos associados com}

a prevenção e controle da

mastite em rebanhos leiteiros:

revisão de literatura

\section{New perspectives and concepts associated with the prevention and control of mastitis in dairy cattle: review of literature}

\section{Resumo}

A classificação dos agentes causadores da mastite bovina em relação a sua forma de transmissão em contagiosa ou ambiental pode variar devido a diferenças de comportamento entre estirpes de micro-organismos dentro de uma mesma espécie. Alguns patógenos classificados como contagiosos demonstraram características de transmissão ambiental, e patógenos classificados como ambientais apresentaram maior adaptação ao hospedeiro. Além disso, o controle e a distribuição dos patógenos causadores de mastite em rebanhos sofreu influência de alterações na indústria leiteira, sobretudo em relação aos sistemas de produção de leite. Grande parte das fazendas de alta produção passou de um sistema extensivo e semiextensivo para sistemas de produção intensivos ou de confinamento. Atualmente, em países desenvolvidos na produção leiteira, observa-se redução de mastite causada por patógenos contagiosos e aumento de infecções intramamárias causadas por patógenos ambientais e patógenos secundários. Apresente revisão tem como objetivo examinar conceitos e perspectivas associados com a prevenção e o controle da mastite em rebanhos leiteiros, especialmente em relação à mastite causada por patógenos ambientais e por patógenos secundários.

\section{Summary}

The classification of the causative agents of bovine mastitis regarding its transmission route as contagious or environmental may vary due to the differences of micro-organisms strains behavior within the species. Some pathogens classified as contagious have shown environmental transmission behavior, whilst pathogens earlier classified as environmental have shown adaptability to the host. Furthermore, the control and distribution of mastitis pathogens in the herds have been influenced by changes in the dairy industry, particularly regarding the milk production systems. Most high-producing dairy farms have changed from extensive or semi-extensive systems to intensive cattle farming or confinement raising systems. Currently, in countries with developed dairy production, it has been observed a reduction of mastitis caused by contagious pathogens and an increase of intramammary infections caused by environmental and minor pathogens. The present literature review aims to examine concepts and perspectives regarding the prevention and control of mastitis in dairy herds, especially those related to mastitis caused by environmental and minor pathogens. 
Tiago Tomazi

Juliano Leonel Gonçalves ${ }^{1}$

Marcos Veiga dos Santos²

Departamento de Nutrição e Produção Animal da Faculdade de Medicina Veterinária e Zootecnia da Universidade de São Paulo; Av. Duque de Caxias Norte, 225, Campus USP Pirassununga CEP 13635-900, Pirassununga - SP, Brasil 四 tiago.tomazi@usp.br

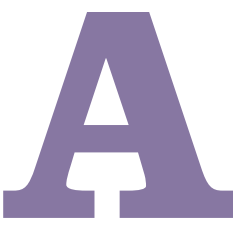

mastite é uma doença multifatorial que afeta a glândula mamária de vacas leiteiras, reduzindo tanto a quantidade quanto a qualidade do leite produzido. Assegurar a sanidade do rebanho e a produção de leite de alta qualidade é objetivo primário de técnicos e médicos veterinários que trabalham em fazendas produtoras de leite. No entanto, apesar de décadas de esforço empregado em programas de controle e prevenção, a mastite continua a ser a doença mais importante e economicamente desafiadora para a bovinocultura de leite (RUEGG, 2012).

Atualmente, em países desenvolvidos na produção leiteira, agentes contagiosos da mastite (Staphylococcus aureus e Streptococcus agalactiae) já foram parcialmente controlados em decorrência de programas específicos de controle e prevenção. Em contrapartida, tem sido relatado aumento da incidência de infecções intramamárias (IIM) causadas por patógenos ambientais (HOGAN; SMITH, 2012) e por patógenos secundários (TAPONEN; PYÖRÄLÄ, 2009).

Para ser considerado efetivo, um programa de controle de mastite depende do conhecimento das formas de transmissão e de fatores epidemiológicos relacionados às espécies com potencial de causar IIM nos rebanhos. Com a disponibilidade de técnicas genotípicas de diagnóstico, a distinção clássica de microrganismos causadores de mastite em ambientais ou contagiosos parece estar perdendo a sustentação. Patógenos classicamente identificados como contagiosos

1 Doutorando do curso de pós-graduação em Nutrição e Produção Animal da Universidade de São Paulo (FMVZ/USP).

2 Professor da Faculdade de Medicina Veterinária e Zootecnia da Universidade de São Paulo (FMVZ/USP). 
apresentaram perfis genotípicos heterogêneos dentro de uma mesma espécie (HAVERI et al., 2007; OLIVEIRA et al., 2011). Esse fato indica que rotas de transmissão diferentes da observada na mastite contagiosa podem estar presentes na epidemiologia de IIM causadas por esses micro-organismos. Da mesma forma, espécies bacterianas gram-negativas, com características de transmissão tipicamente ambiental, têm apresentado adaptação à glândula mamária do hospedeiro e homogeneidade genotípica intraespecífica (MUNOZ et al., 2007), o que indica um perfil de transmissão contagioso.

Dessa forma, a simples identificação em nível de espécie pode não ser suficiente para o diagnóstico definitivo do perfil de transmissão da mastite em nível de rebanho (SCHUKKEN et al., 2012). Técnicas moleculares avançadas, que possibilitam a identificação de subtipos bacterianos intraespecíficos, são mais precisas para a determinação do perfil de transmissão de IIM em nível de rebanho. Assim, programas de prevenção e tratamento específicos podem ser propostos aos produtores de leite, a fim de controlar a mastite e melhorar a sanidade das vacas.

A presente revisão tem como objetivo descrever as novas perspectivas e conceitos associados com a prevenção e controle da mastite em rebanhos leiteiros, especialmente em relação à mastite causada por patógenos ambientais e patógenos secundários.

\section{Conceitos sobre a mastite}

A mastite é uma inflamação da glândula mamária que pode ter origem infecciosa ou não infecciosa, sendo caracterizada por alterações físicas, químicas e normalmente microbiológicas do leite. As principais causas infecciosas da mastite são bactérias, fungos, leveduras e algas.

A mastite é considerada a doença mais importante da produção leiteira e apresenta grande influência sobre a lucratividade dos produtores e de toda a cadeia agroindustrial do leite. Infecções intramamárias resultam em perdas econômicas significativas que estão

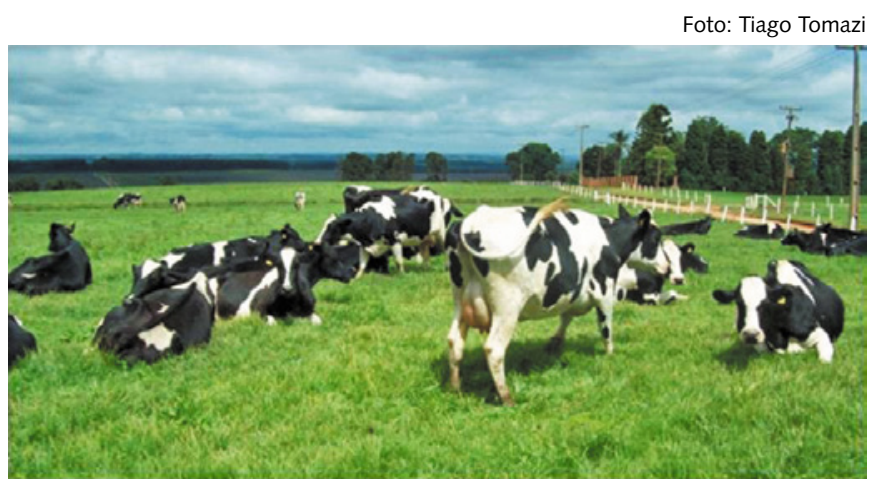

Vacas em ambiente limpo no sistema de pastagem são menos suscetíveis à mastite

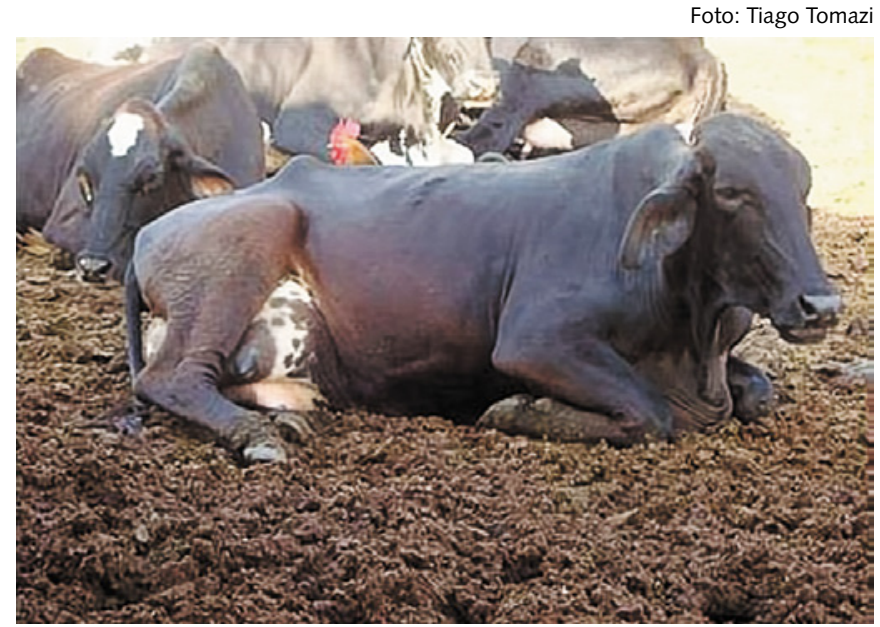

Vacas deitadas em ambiente com excesso de umidade e matéria orgânica correm risco

associadas com a redução na produção de leite (mais de $70 \%$ ), o custo com tratamento e encargos médicoveterinários $(7 \%)$, o descarte de leite durante o período de tratamento (9\%), o aumento da mão-de-obra (1\%) e o descarte prematuro de animais (14\%) (MILLER et al., 1993; SHARMA et al., 2012).

Após o desenvolvimento de um processo infeccioso, ocorrem lesões no epitélio mamário e consequente perda de funcionalidade do tecido glandular e secretor de leite, o que resulta em redução do potencial de produção de vacas acometidas (BRADLEY, 2002). O processo de IIM é iniciado quando micro-organismos patogênicos invadem o canal do teto e multiplicam-se no interior dos tecidos mamários. Após a invasão da glândula mamária, ocorre intensa migração de leucócitos do sangue para o leite, com o objetivo de eliminar o agente infeccioso, bem como reduzir a permeabilidade vascular e outros sinais da inflamação. A resposta inflamatória desencadeada pelo processo infeccioso tem por objetivo a eliminação do micro-organismo causador, a neutralização de toxinas e a regeneração dos tecidos danificados (SANTOS; FONSECA, 2006).

A maior parte dos casos de mastite bovina é de etiologia bacteriana e, uma vez acometido, o quarto mamário com mastite pode evoluir para cura espontânea ou, na maioria das vezes, para um quadro crônico, tornandose necessária a identificação do agente causador para adequar as medidas de controle e tratamento (OLIVER et al., 2004).

\section{Novas perspectivas para o controle e tratamento}

A classificação da mastite quanto ao agente etiológico em contagiosa ou ambiental tem sido baseada nos reservatórios primários e principalmente no modo de transmissão dos patógenos causadores. Com o uso da classificação tradicional, o úbere de vacas com infecções subclínicas atua 
como reservatório primário para agentes contagiosos. A transmissão de patógenos contagiosos ocorre quando tetos de vacas sadias são expostos a microrganismos presentes em quartos mamários infectados. A forma mais comum de um quarto mamário sadio contrair mastite contagiosa ocorre pelo contato com bactérias presentes nas teteiras, após a ordenha de tetos infectados. Entretanto, a transmissão pela via contagiosa pode ocorrer por qualquer micro-organismo que possa se multiplicar no leite e estabelecer uma população infectante que supere as defesas imunológicas da vaca (RUEGG, 2012).

A denominação de patógenos contagiosos ou ambientais se difundiu antes do surgimento das metodologias de identificação moleculares de micro-organismos. O uso de fingerprintings de DNA e outras metodologias moleculares apresentam resultados controversos quanto à classificação da mastite pelo perfil de transmissão ambiental ou contagioso dos micro-organismos (RUEGG, 2012). Tem sido observada grande diversidade genotípica de estirpes supostamente classificadas como patógenos contagiosos, isoladas de amostras de leite entre diferentes rebanhos e dentro de um mesmo rebanho (OLIVEIRA et al., 2011). Dessa forma, a transmissão de algumas espécies de patógenos classificados como contagiosos pode estar ocorrendo por rotas diferentes da contagiosa (vaca-vaca). Da mesma forma, foi relatada a ocorrência de patógenos ambientais gram-negativos adaptados ao hospedeiro (MUNOZ et al., 2007; ZADOKS et al., 2011).

À medida que o uso de técnicas de identificação de micro-organismos por meio de biologia molecular tornase mais comum em laboratórios, é provável que as formas de infecção e transmissão da mastite sejam mais bem entendidas. Possivelmente, em um futuro próximo, os programas preventivos da mastite irão atentar para rotas múltiplas de transmissão, independentemente da classificação dos patógenos. Ao se depararem com um problema

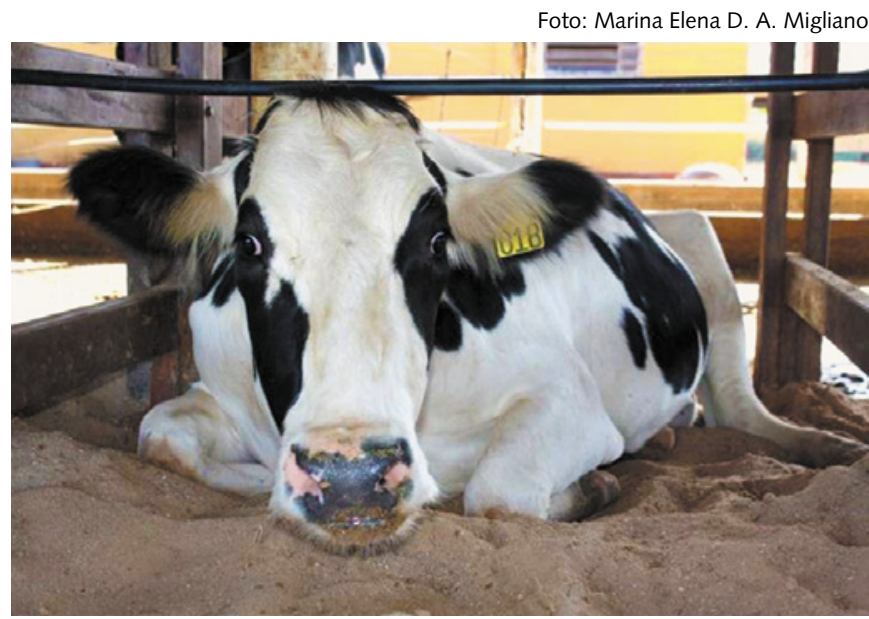

Vaca em condições adequadas de bem-estar deitada em cama de areia com bom manejo

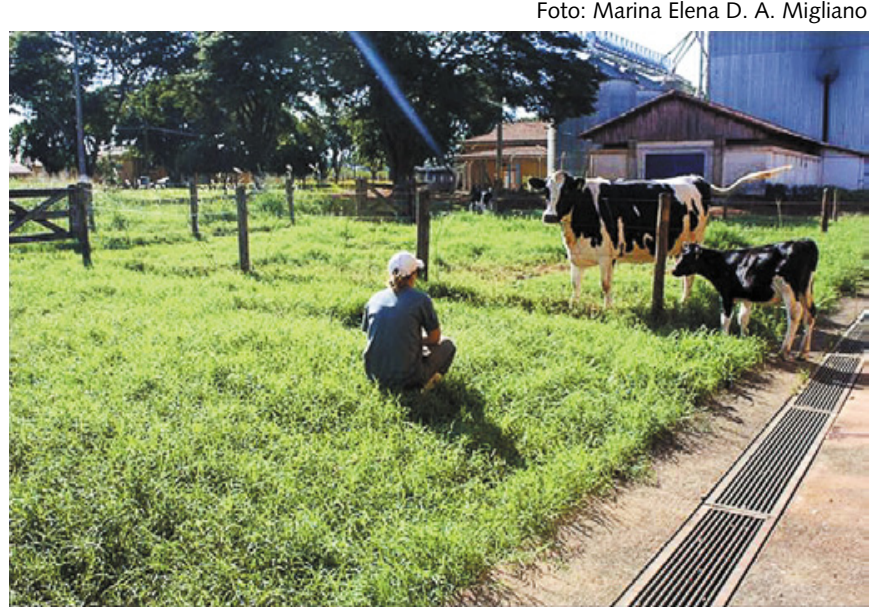

Manutenção da higiene e limpeza do ambiente em todos os locais da fazenda, desde a criação das bezerras até o local de produção leiteira reduzem a incidência de mastite

de mastite, os veterinários terão de usar seus conhecimentos epidemiológicos para investigar fatores de risco relacionados à transmissão em cada fazenda, sem necessariamente utilizar a classificação tradicional relacionada com as rotas de transmissão contagiosa ou ambiental.

Atualmente, o controle da mastite tem sido influenciado por alterações na indústria leiteira, sobretudo quanto aos sistemas de produção de leite. Em países desenvolvidos na produção leiteira, as vacas passaram de sistemas de produção extensivos e semiextensivos para sistemas intensivos de confinamento. Essas alterações na estrutura dos rebanhos resultaram em mudanças na distribuição dos agentes causadores de mastite (RUEGG, 2012). Além disso, a adoção do programa de cinco pontos de controle da mastite contagiosa (1: desinfecção dos tetos pós-ordenha; 2: terapia de vaca seca em todos os animais; 3: tratamento apropriado dos casos clínicos; 4: descarte de vacas cronicamente infectadas; e 5: manutenção periódica do sistema de ordenha) resultou em redução expressiva de prevalência de agentes contagiosos (MAKOVEC; RUEGG, 2003; BRADLEY et al., 2007). Em consequência ao controle direcionado de patógenos contagiosos, tem-se observado aumento da incidência de IIM causadas por patógenos ambientais (HOGAN; SMITH, 2012) e por patógenos secundários (TAPONEN; PYÖRÄLÄ, 2009; THORBERG et al., 2009).

\section{Controle da mastite causada por patógenos ambientais} Os patógenos ambientais são descritos como invasores oportunistas da glândula mamária. Normalmente, os patógenos ambientais invadem a glândula mamária, multiplicam-se, desencadeiam uma resposta imune no hospedeiro e são rapidamente eliminados (BRADLEY, 2002). Os principais patógenos ambientais da mastite podem ser tanto bactérias gram-positivas $(S$. uberis e $S$. 
dysgalactiae) quanto bactérias gram-negativas (E. coli e Klebsiella spp.) (HOGAN; SMITH, 2012). A duração de IIM causada por patógenos ambientais varia entre os micro-organismos causadores e pode ser associada com o grau de adaptação ao hospedeiro. Alguns patógenos ambientais, como a $E$. coli, são totalmente oportunistas e a resposta imune da vaca normalmente elimina esses patógenos após um breve período de quadro clínico moderado. Foi constatado que os patógenos ambientais causadores de mastite, como S. uberis e Klebsiella spp., podem estar mais adaptados ao hospedeiro. Esses agentes podem causar casos clínicos leves que posteriormente aparentam estar curados, porém, apenas retornaram para um quadro subclínico (HOGAN; SMITH, 2012).

A mastite ambiental é caracterizada pelo aumento do número de casos clínicos e não apresenta alterações significativas na CCS do leite de tanque. Problemas com mastite clínica em propriedades leiteiras são menos percebidos pelo médico veterinário responsável e são mais difíceis de serem investigados, pois, na maioria das vezes, as vacas recebem terapia antimicrobiana e os casos clínicos não são registrados (HOE; RUEGG, 2006). Práticas de manejo que visam evitar a exposição das vacas aos patógenos ambientais são dificultadas devido às diferenças entre os grupos de animais em responder aos desafios ambientais. Por exemplo, a maior ocorrência de mastite clínica no início da lactação é uma característica de IIM causada por patógenos ambientais. Embora a exposição aos patógenos potencialmente ambientais ocorra durante todo o ciclo de lactação, vacas no periparto apresentam maior predisposição à IIM devido à imunossupressão que ocorre nesse período (HOGAN; SMITH, 2012).

Entretanto, práticas de manejo devem ser direcionadas para prevenção do primeiro caso de mastite da

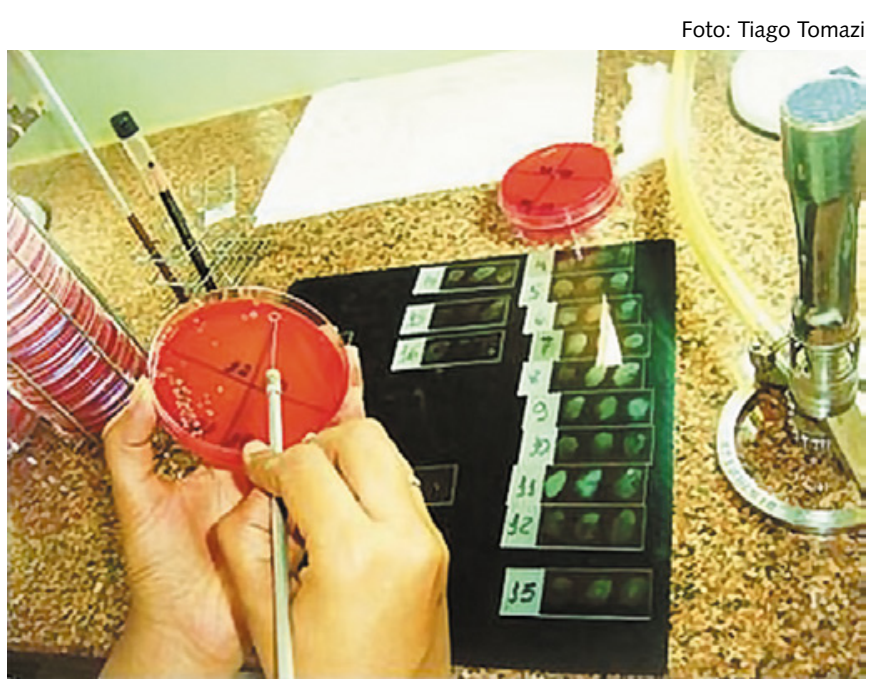

Diagnóstico do perfil de patógenos causadores de mastite por meio de cultura microbiológica auxilia na tomada de decisão em relação ao controle da mastite no rebanho vaca, pois a ocorrência de mastite clínica é um preditor importante do futuro risco da doença, tanto na lactação intercorrente, quanto nas lactações futuras (PANTOJA; HULLAND; RUEGG, 2009a, b; PINZÓN-SÁNCHEZ; RUEGG, 2011). O exame de 218 vacas multíparas que apresentaram um caso clínico de mastite na lactação anterior revelou que esses animais apresentaram 4,2 vezes mais probabilidade de ter um novo caso nos primeiros 120 dias de lactação do que vacas que completaram a lactação anterior sem ocorrência de mastite (PANTOJA; HULLAND; RUEGG, 2009a). Esses resultados foram observados mesmo quando o quarto afetado apresentou-se microbiologicamente negativo após o parto.

A chave para o controle da mastite ambiental é a redução da exposição das vacas aos patógenos presentes no ambiente. Espécies bacterianas ambientais são micro-organismos quimiotrópicos que requerem material orgânico como fonte de nutrientes. Coliformes e estreptococos ambientais não são capazes de sobreviver na pele do teto por longos períodos de tempo. A alta contagem de coliformes e estreptococos ambientais na pele e esfíncter do teto é característica de contaminação recente, provavelmente devido ao ambiente em condições inadequadas de higiene e limpeza (RENDOS; EBERHART; KESLER, 1975; ZDANOWICZ et al., 2004). Vacas permanecem deitadas de 12 a 14 horas por dia e os seus tetos estão em contato direto com a cama ou outros materiais onde descansam. Populações de bactérias na cama ou em outros materiais são positivamente correlacionados com o número de bactérias no esfíncter do teto e com taxas de mastite clínica (HOGAN et al., 1989; ZDANOWICZ et al., 2004).

A redução da exposição aos patógenos ambientais da mastite é difícil devido às limitações estruturais das áreas onde as vacas são alojadas. A intensificação dos sistemas de alojamento de vacas leiteiras normalmente resulta na exposição dos tetos a uma grande variedade de potenciais patógenos da mastite. $\mathrm{O}$ manejo do esterco, o tipo de cama, a arquitetura do estábulo e a densidade populacional podem ter grande impacto sobre a exposição do úbere aos potenciais patógenos da mastite. Camas compostas de material inorgânico apresentam menor teor de umidade e menor concentração de nutrientes para a multiplicação microbiana. $\mathrm{O}$ material inorgânico mais recomendado para a cama de vacas leiteiras com o objetivo de controlar a mastite ambiental é a areia lavada. Comparada com materiais orgânicos como serragem, esterco reciclado, palha e terra, a areia lavada contém aproximadamente 100 vezes menos patógenos da mastite por grama de cama (HOGAN et al., 1989). No entanto, com o aumento do acúmulo de material orgânico e 
umidade na cama, decorrente da reutilização da areia, ocorre rápido aumento de patógenos causadores de mastite (KRISTULA et al., 2005).

Apesar de os materiais orgânicos conterem relativamente menos patógenos antes da utilização, sua população aumenta até 10.000 vezes em algumas horas, após seu uso nas camas das vacas (GOOCH et al., 2006). Independentemente do tipo de material utilizado, a remoção da umidade e sujidades do terço final da cama, onde os úberes estão em contato direto com o piso, reduz significativamente as contagens bacterianas. Os currais devem ser limpos no mínimo duas vezes ao dia, quando os animais são levados para ordenha (HOGAN; SMITH, 2012).

A superlotação aumenta a quantidade de fezes nos galpões e corredores. As fezes acumuladas nestes locais se grudam nos cascos e pernas das vacas e, posteriormente, contaminam as camas com bactérias fecais. Outros fatores que afetam o risco de mastite ambiental são temperatura e umidade. As taxas de crescimento de coliformes e estreptococos ambientais aumentam em estações quentes e chuvosas. Hogan et al. (1990) observaram alta correlação entre as contagens bacterianas da cama e a temperatura ambiental e a umidade relativa do ar. Além disso, a superlotação dos galpões pode exacerbar os efeitos negativos do calor e da umidade.

Piquetes cobertos e com piso de terra são normalmente utilizados para alocar vacas no período seco. Conforme a densidade de vacas aumenta nesses piquetes, principalmente em locais de sombra e entorno de cochos e bebedouros, ocorre acúmulo de material orgânico úmido que deve ser removido e drenado, a fim de propiciar um ambiente seco para as vacas.

Em sistemas de pastagem, a carga de patógenos ambientais normalmente é reduzida em comparação com sistemas de confinamento total. Solos cobertos com plantas forrageiras em piquetes de pastagem normalmente apresentam contaminação mínima com patógenos ambientais da mastite. No entanto, a exposição dos tetos às bactérias aumenta quando a oferta de pasto nos piquetes diminui devido à superlotação e manejo inadequado de rotação de piquetes (GREEN et al., 2007; LOPEZ-BENAVIDES et al., 2007). A radiação solar e a manutenção de um ambiente seco reduzem a carga bacteriana em pastagens e piquetes destinados às vacas secas ou em período pré-parto.

A manutenção da higiene dos piquetes de maternidade deve ser vista como prioridade em um programa de controle de mastite ambiental. As práticas de manejo destinadas à redução da exposição do úbere aos patógenos da mastite nas áreas de vaca seca e maternidade são similares àquelas utilizadas nas instalações de vacas em lactação. Tais áreas devem ser limpas e drenadas para evitar o acúmulo de umidade e matéria orgânica.

A higiene do ambiente de ordenha é a base para o controle da mastite contagiosa e tem menor influência sobre a mastite ambiental. O uso de soluções desinfetantes para imersão dos tetos após a ordenha apresenta poucos efeitos sobre a incidência de IIM causadas por coliformes e estreptococos ambientais. A maioria dos germicidas destrói efetivamente e rapidamente microrganismos presentes na pele dos tetos por ação química ou biológica. No entanto, a persistência da atividade germicida é limitada e neutralizada pelo acúmulo de material orgânico como leite, fezes ou barro (HOGAN; SMITH, 2012).

\section{Controle da mastite causada por patógenos secundários} Patógenos secundários que afetam a glândula mamária, em especial, Corynebacterium spp. e Staphylococcus coagulase-negativa (SCN) têm se tornado os agentes causadores de mastite mais predominantes em rebanhos leiteiros (BRITO et al., 1999; SUPRÉ et al., 2011). Atualmente, em países onde os agentes primários da mastite estão bem controlados, os agentes secundários têm se tornado microrganismos emergentes e importantes causas de IIM em vacas leiteiras (PYÖRÄLÄ; TAPONEN, 2009).

Ainda que sejam considerados agentes secundários da mastite bovina e com menores alterações na CCS e composição do leite, Corynebacterium spp. e SCN são altamente prevalentes nos rebanhos leiteiros. No entanto, os resultados do efeito desses agentes sobre a saúde da glândula mamária ainda são considerados inconclusivos. Victória et al. (2005) e Taponen e Pyörälä (2009) classificam esses agentes como causa importante da mastite bovina e da redução na produção de leite. Por outro lado, Schukken et al. (2009) classificam tais microrganismos como patógenos secundários da mastite, com impacto limitado na produção e qualidade do leite. Além disso, Sordillo et al. (1989) e Reyher et al. (2012) sugerem efeito protetor desses microrganismos na glândula mamária frente a agentes primários causadores de mastite, com inclusive, aumentos na produção leiteira

Sampimon et al. (2009); Sampimon et al. (2010) e Piepers et al. (2011) descreveram SCN como os microorganismos mais comumente isolados de amostras de leite. A alta prevalência de SCN indica a importância desses patógenos na etiologia da mastite de vacas leiteiras. Staphylococcus coagulase negativa são mais frequentemente isolados de vacas e, especialmente, novilhas com mastite subclínica ou clínica com sinais moderados de inflamação, e pouca ou nenhuma alteração da composição do leite (TOMAZI, 2013). 
Dezesseis espécies de SCN já foram isoladas de amostras de leite (CAPURRO et al., 2009) e as diferenças epidemiológicas e de virulência entre as espécies foram destacadas por Thorberg et al. (2009). A tomada de decisão em relação às práticas de manejo e controle da mastite é dependente da classificação da doença (contagiosa ou ambiental). Assim, determinar a epidemiologia das espécies de SCN potencialmente mais patogênicas pode ser importante para as fazendas leiteiras. A distribuição das espécies de SCN isoladas do leite e do ambiente difere entre rebanhos e, da mesma forma, os reservatórios primários diferem de acordo com a espécie envolvida (PIESSENS et al., 2011). Isso é indicativo de que fatores em nível de rebanho ou condições de ambiente determinam a prevalência de espécies de SCN em rebanhos leiteiros. Quando se comparou a distribuição de espécies de SCN nos diferentes locais da fazenda, certas espécies apresentaram variação de afinidade e potencial de multiplicação. Staphylococcus chromogenes e $S$. epidermidis foram predominantemente isolados do leite ( 78,8 e $57,1 \%$ de todos os isolados, respectivamente), e foram menos frequentes em amostras coletadas do ambiente. Staphylococcus haemolyticus e $S$. simulans foram regularmente isolados, tanto de amostras de leite quanto do ambiente. Espécies com origem predominantemente ambiental (100\% dos isolados) foram o S. equorum, S. sciuri, S. fleuretti, S. cohnii, S. devriesei, S. xylosus, S. arlettae e $S$. succinus. As espécies de SCN com características ambientais também estavam diferentemente distribuídas nos locais avaliados. Staphylococcus haemolyticus e S. equorum foram isolados principalmente do ar, enquanto $S$. sciuri e $S$. simulans foram isolados principalmente do piso e da cama em uso, respectivamente. Staphylococcus xylosus e S. succinus foram isolados com maior frequência do estoque de areia para cama (PIESSENS et al., 2011).

A decisão sobre o melhor protocolo de tratamento da mastite causada por SCN não é consensual entre os médicos veterinários. A maioria dos pesquisadores concorda que a mastite causada por SCN resulta em altas taxas de cura espontânea e que esses micro-organismos apresentam boa resposta ao tratamento antimicrobiano (RUEGG, 2012). Com base nas informações disponíveis em relação ao tratamento da mastite causada por SCN, as taxas de cura variaram de $80 \%$ a $90 \%$ com o uso de antimicrobianos (MCDOUGALL, 1998; WAAGE et al., 2000; TAPONEN et al., 2003). Vacas com maior número de lactações apresentaram menores chances de cura que as mais jovens (DELUYKER; VAN OYE; BOUCHER, 2005).

Um único isolamento de SCN de um quarto mamário não justifica economicamente a terapia antimicrobiana, em particular, quando somente um pequeno número de colônias for detectado em uma amostra de leite. Staphylococcus coagulase negativa são bactérias comuns da pele do teto e podem, em algumas situações, contaminar a amostra de leite. Além disso, a taxa de eliminação espontânea das IIM causadas por SCN sem a utilização de qualquer tratamento é alta. O tratamento é recomendado se forem evidenciados sinais clínicos de grau moderado a grave. O tratamento de IIM com antimicrobianos também pode ser recomendado em casos de mastite persistente causada por SCN (PYÖRÄLÄ; TAPONEN, 2009). Para os casos de mastite persistente, a terapia de vaca seca permanece sendo a melhor ferramenta devido às taxas de cura mais altas proporcionadas por essa prática de manejo (NEWTON et al., 2008).

A diversidade de espécies que compõem o grupo de SCN, bem como as diferenças epidemiológicas entre estas espécies, faz com que práticas de manejo sejam direcionadas para prevenir ambas as vias de transmissão, a contagiosa e a ambiental. Espécies como S. chromogenes e S. epidermidis parecem ser bem adaptadas à glândula mamária e é possível que essas espécies estejam relacionadas com a transmissão contagiosa (PIESSENS et al., 2012). Medidas de controle relacionadas ao manejo correto de ordenha e que são utilizadas na prevenção de patógenos contagiosos, como a desinfecção dos tetos após a ordenha, reduziram as IIM causadas por SCN nos rebanhos leiteiros (HOGAN et al., 1995).

Dentre outras medidas preventivas contra mastite durante o período seco, o uso de selantes internos tem sido utilizado como uma alternativa ou complemento à terapia de vaca seca. O seu emprego em novilhas reduziu o risco de mastite após o parto, inclusive as causadas por SCN (PARKER et al., 2007).

O pico de prevalência de SCN ocorre durante o período pré-parto, com redução gradual durante a lactação (OLIVER; JAYARAO, 1997). O manejo e higiene dos piquetes de maternidade devem ser vistos como prioridade em um programa de controle de mastite. As práticas de manejo com o objetivo de reduzir a exposição do úbere aos patógenos da mastite nas áreas de vaca seca e maternidade são similares àquelas utilizadas nas instalações de vacas em lactação. Tais áreas devem ser limpas e drenadas para evitar o acúmulo de matéria orgânica (HOGAN et al., 1999). O controle da mastite causada por espécies de SCN é difícil devido à impossibilidade de erradicação desses patógenos no ambiente. Entretanto, as práticas de manejo preventivo devem objetivar a redução da umidade e a manutenção da higiene dos piquetes e instalações de vacas e novilhas durante o pré-parto. 
O grupo SCN é formado por grande variedade de espécies com potencial de adaptação tanto ao ambiente quanto na glândula mamária. Entretanto, o conhecimento epidemiológico sobre as espécies de SCN envolvidas na mastite pode auxiliar na decisão de estratégias direcionadas de manejo, a fim de prevenir as IIM causadas por esses patógenos em rebanhos leiteiros.

Outro gênero de patógenos secundários da mastite com alta prevalência em rebanhos leiteiros é o Corynebacterium spp. Da mesma forma que o SCN, o Corynebacterium spp. é considerado um patógeno secundário, que acomete principalmente vacas durante a lactação, com potencial de causar sinais clínicos leves e aumentos moderados de CCS (HUXLEY; HELPS; BRADLEY, 2004; BRADLEY; GREEN, 2005). A principal espécie de Corynebacterium isolada em amostras de leite é o Corynebacterium bovis, que, em geral, causa mastite com sintomas leves e com pouca alteração na CCS e na constituição físico-química do leite (HUXLEY; GREEN; BRADLEY, 2003). No entanto, Corynebacterium spp. já foi isolado em casos de mastite clínica e foi responsável por alterações significativas em nível celular por longos períodos de tempo (COSTA et al., 1985; SCHUKKEN et al., 1989). A ocorrência sob a forma de surto, e a capacidade de provocar mastite clínica persistente, classifica o Corynebacterium spp. como agente com caráter contagioso na epidemiologia da mastite (COSTA et al., 1985).

A espécie C. bovis prontamente coloniza o canal do teto de vacas leiteiras e seu isolamento é considerado um indicador de higiene no momento da ordenha (WATTS et al., 2000). Corynebacterium bovis foi isolado em mais de $60 \%$ dos quartos amostrados de vacas onde a desinfecção dos tetos pós-ordenha não foi uma prática de rotina em rebanhos (Woodward et al., 1987). Brito et al. (1999), avaliando os fatores epidemiológicos associados à mastite, constataram que, em rebanhos onde se observou alta prevalência de Corynebacterium spp, as medidas de controle para as mastites contagiosas não foram corretamente aplicadas. Produtos cujo princípio ativo foi o LDBSA (ácido sulfônico linear duodecilbezeno) não apresentaram resultados satisfatórios na desinfecção dos tetos contra Corynebacterium spp. (NMC, 1999). Por outro lado, produtos à base de iodo e clorexidina foram eficazes para a desinfecção dos tetos pós-ordenha (TIMM et al., 2000).

Em termos de controle de infecções subclínicas causadas por C. bovis, além da desinfecção dos tetos após a ordenha, a terapia da vaca seca com uso de antimicrobianos também é uma prática recomendada. Durante a lactação não se recomenda o tratamento dos casos subclínicos causados por Corynebacterium spp.

\section{Considerações Finais}

O conhecimento epidemiológico sobre os agentes causadores da mastite, em especial, em relação às rotas de transmissão desses patógenos é imprescindível em um programa de controle e prevenção desta doença. A mastite pode ser controlada pela prevenção de novas infecções e eliminação de infecções existentes Porém, fazendas leiteiras são sistemas complexos de produção e a implementação de um plano de sanidade de úbere pode ser demorada. O sucesso dos programas de sanidade de úbere é dependente da detecção efetiva da mastite, do diagnóstico preciso dos patógenos envolvidos, da avaliação de opções de tratamento apropriadas, e da implementação de práticas preventivas rebanho-específicas, associadas aos fatores de risco relacionados à exposição das vacas aos patógenos.

Profissionais que pretendem atuar em programas de sanidade de úbere devem regularmente consultar os registros de CCS e ajudar a desenvolver sistemas para monitorar as taxas de mastite clínica, com base na avaliação dos indicadores de desempenho relativos às metas da fazenda. Dados devem ser coletados e registrados rotineiramente, de modo que se torne mais fácil a avaliação de fatores ligados à vaca, ao ambiente, e aos equipamentos de ordenha. $\mathrm{O}$ médico veterinário responsável e o proprietário da fazenda devem desenvolver um planejamento anual de sanidade de úbere, a fim de alcançar as metas propostas. As metas relacionadas à qualidade do leite devem ser revistas anualmente e serem suportadas por um planejamento que defina ações específicas com delineamento claro e com responsabilidade de execução. 


\section{Referências}

1. BRADLEY, A. J. Bovine mastitis: an evolving disease. Veterinary Journal, v. 164, n. 2, p. $116-128,2002$.

2. BRADLEY, A. J.; LEACH, K. A.; BREEN, J. E.; GREEN, L. E.; GREEN, M. J. Survey of the incidence and aetiology of mastitis on dairy farms in England and Wales. Veterinary Record, v. 160, n. 8, p. 253-257, 2007

3. BRADLEY, A.; GREEN, M. Use and interpretation of somatic cell count data in dairy cows. Farm Animal Practice, v. 27, n. 6, p. 310-315, 2005

4. BRITO, M. A. V. P.; BRITO, J. R. F.; RIBEIRO, M. T.; VEIGA, V. M. O. Padrão de infecção intramamária em rebanhos leiteiros: exame de todos os quartos mamários das vacas em lactação. Arquivo Brasileiro de Medicina Veterinária e Zootecnia, v. 51, n. 2, p. $129-135,1999$

5. CAPURRO, A.; ARTURSSON, K.; WALLER, K. P.; BENGTSSON, B.; ERICSSONUNNERSTAD, H.; ASPÁN, A. Comparison of a commercialized phenotyping system, antimicrobial susceptibility testing, and tuf gene sequence-based genotyping for species-level identification of coagulase-negative staphylococci isolated from cases of bovine mastitis. Veterinary Microbiology, v. 134, n. 3-4, p. 327-333, 2009

6. COSTA, E. O.; CARVALHO, V. M.; COUTINHO, S. D.; CASTILHO, W.; COROMORI, L. F. L. Corynebacterium bovis e sua importância na etiologia da mastite bovina no Estado de São Paulo. Pesquisa Veterinária Brasileira, v. 5, n. 4, p. 117-120, 1985

7. DELUYKER, H. A.; VAN OYE, S. N.; BOUCHER, J. F. Factors affecting cure and somatic cell count after pirlimycin treatment of subclinical mastitis in lactating cows. Journal Dairy Science, v. 88, n. 2, p. 604-614, 2005.

8. GOOCH, C. A.; HOGAN, J. S.; GLAZIER, N.; NOBLE, R. Use of post-digested separated manure solids as freestall bedding: a case study. In: ANNUAL CONFERENCE NATIONAL MASTITIS COUNCIL, 46., 2006, Tampa, FL. Proceedings... Tampa, FL., 2006. p. 151-160.

9. GREEN, M. J.; BRADLEY, A. J.; MEDLEY, G. F.; BROWNE, W. J. Cow, farm, and management factors during the dry period that determine the rate of clinical mastitis after calving. Journal Dairy Science, v. 90, n. 8, p. 3764-3776, 2007.

10. HAVERI, M.; ROSLO, A.; RANTALA, L.; PYORALA, S. Virulence genes of bovine Staphylococcus aureus from persistent and nonpersistent intramammary infections with different clinical characteristics. Journal Applied Microbiology, v. 103, n. 4, p. 993-1000, 2007

11. HOE, F. G. H.; RUEGG, P. L. Opinions and practices of Wisconsin dairy producers about biosecurity and animal well-being. Journal Dairy Science, v. 89, n. 6, p. 2297-2308, 2006.

12. HOGAN, J. S.; BOGACZ, V. L.; THOMPSON, L. M.; ROMIG, S.; SCHOENBERGER, P. S.; WEISS, W. P.; SMITH, K. L. Bacterial counts associated with sawdust and recycled manure bedding treated with commercial conditioners. Journal Dairy Science, v. 82, n. 8, p. $1690-1695,1999$.

13. HOGAN, J. S.; SMITH, K. L.; HOBLET, K. H.; TODHUNTER, D. A.; SCHOENBERGER, P. S.; HUESTON, W. D.; PRITCHARD, D. E.; BOWMAN, G. L.; HEIDER, L. E.; BROCKETT, B. L.; CONRAD, H. R. Bacterial counts in bedding materials used on 9 commercial dairies. Journal Dairy Science, v. 72, n. 1, p. 250-258, 1989.

14. HOGAN, J. S.; SMITH, K. L.; TODHUNTER, D. A.; SCHOENBERGER, P. S. Bacterial counts associated with recycled newspaper bedding. Journal Dairy Science, v. 73, n. 7, p. $1756-1761,1990$

15. HOGAN, J. S.; SMITH, K. L.; TODHUNTER, D. A.; SCHOENBERGER, P. S. Efficacy of a barrier teat dip containing $55 \%$ chlorhexidine for prevention of bovine mastitis. Journal Dairy Science, v. 78, n. 11, p. 2502-2506, 1995.
16. HOGAN, J.; SMITH, K. L. Managing environmental mastitis. Veterinary Clinics North America: food animal practice, v. 28, n. 2, p. 217-224, 2012.

17. HUXLEY, J. N.; HELPS, C. R.; BRADLEY, A. J. Identification of Corynebacterium bovis by endonuclease restriction analysis of the $16 \mathrm{~S}$ rRNA gene sequence. Journal Dairy Science, v. 87, n. 1, p. 38-45, 2004.

18. HUXLEY, J. N.; GREEN, M. J.; BRADLEY, A. J. Corynebacterium bovis - friend or foe? In: BRITISH MASTITIS CONFERENCE, 2003, Garstang. Proceedings... Garstang: Institute for Animal Health, 2003. p. 23-24.

19. KRISTULA, M. A.; ROGERS, W.; HOGAN, J. S.; SABO, M. Comparison of bacteria populations in clean and recycled sand used for bedding in dairy facilities. Journal Dairy Science, v. 88, n. 12, p. 4317-4325, 2005

20. LOPEZ-BENAVIDES, M. G.; WILLIAMSON, J. H.; PULLINGER, G. D.; LACY-HULBERT, S. J.; CURSONS, R. T.; LEIGH, J. A. Field observations on the variation of Streptococcus uberis populations in a pasture-based dairy farm. Journal Dairy Science, v. 90, n. 12, p. 5558-5566, 2007.

21. MAKOVEC, J. A.; RUEGG, P. L. Results of milk samples submitted for microbiological examination in Wisconsin from 1994 to 2001. Journal Dairy Science, v. 86, n. 11, p. 3466-3472, 2003.

22. MCDOUGALL, S. Efficacy of two antibiotic treatments in curing clinical and subclinical mastitis in lactating dairy cows. New Zealand Veterinary Journal, v. 46, n. 6, p. 226232, 1998.

23. MILLER, G. Y.; BARTLETT, P. C.; LANCE, S. E.; ANDERSON, J.; HEIDER, L. E. Costs of clinical mastitis and mastitis prevention in dairy herds. Journal American Veterinary Medical Association, v. 202, n. 8, p. 1230-1236, 1993

24. MUNOZ, M. A.; WELCOME, F. L.; SCHUKKEN, Y. H.; ZADOKS, R. N. Molecular epidemiology of two Klebsiella pneumoniae mastitis outbreaks on a dairy farm in New York State. Journal Clinical Microbiology, v. 45, n. 12, p. 3964-3971, 2007.

25. NMC. NATIONAL MASTITIS COUNCIL. Current concepts of bovine mastitis. 4th ed. Madison: WI, NMC Inc., 1999. p. 1-64.

26. NEWTON, H. T.; GREEN, M. J.; BENCHAOUI, H.; CRACKNELL, V.; ROWAN, T.; BRADLEY, A. J. Comparison of the efficacy of cloxacillin alone and cloxacillin combined with an internal teat sealant for dry-cow therapy. Veterinary Record, v. 162, n. 21, p. 678-684, 2008.

27. OlIVEIRA, L.; RODRIGUES, A. C.; HULLAND, C.; RUEGG, P. L. Enterotoxin production, enterotoxin gene distribution, and genetic diversity of Staphylococcus aureus recovered from milk of cows with subclinical mastitis. American Journal Veterinary Research, v. 72, n. 10, p. 1361-1368, 2011

28. OLIVER, S. P.; JAYARAO, B. M. Coagulase-negative staphylococcal intramammary infections in cows and heifers during the nonlactating and periparturient periods. Journal Veterinary Medicine. Series B Infectious Diseases Veterinary Public Health, v. 44, n. 6, p. 355-363, 1997.

29. OLIVER, S. P.; HOGAN, J. S.; JAYARAO, B. M.; OWENS, W. E. Microbiological procedures for the diagnosis of bovine udder infection and determination of milk quality. 4th ed. Verona, WI: National Mastitis Council Inc., 2004.

30. PANTOJA, J. C. F.; HULLAND, C.; RUEGG, P. L. Dynamics of somatic cell counts and intramammary infections across the dry period. Preventive Veterinary Medicine, v. 90, n. $1-2$, p. $43-54,2009 a$. 
31. PANTOJA, J. C. F.; HULLAND, C.; RUEGG, P. L. Somatic cell count status across the dry period as a risk factor for the development of clinical mastitis in the subsequent lactation. Journal Dairy Science, v. 92, n. 1, p. 139-148, 2009b.

32. PARKER, K. I.; COMPTON, C.; ANNISS, F. M.; WEIR, A.; HEUER, C.; MCDOUGALL, S Subclinical and clinical mastitis in heifers following the use of a teat sealant precalving Journal Dairy Science, v. 90, n. 1, p. 207-218, 2007.

33. PIEPERS, S.; PEETERS, K.; OPSOMER, G.; BARKEMA, H. W.; FRANKENA, K.; DE VLIEGHER, S. Pathogen group specific risk factors at herd, heifer and quarter levels for intramammary infections in early lactating dairy heifers. Preventive Veterinary Medicine, v. 99, n. 2-4, p. 91-101, 2011.

34.PIESSENS, V.; DE VLIEGHER, S.; VERBIST, B.; BRAEM, G.; VAN NUFFEL, A.; DE VUYST, L.; HEYNDRICKX, M.; VAN COILLIE, E. Characterization of coagulasenegative staphylococcus species from cows' milk and environment based on bap, icaA, and mecA genes and phenotypic susceptibility to antimicrobials and teat dips. Journal Dairy Science, v. 95, n. 12, p. 7027-7038, 2012.

35. PIESSENS, V.; VAN COILLIE, E.; VERBIST, B.; SUPRÉ, K.; BRAEM, G.; VAN NUFFEL, A.; DE VUYST, L.; HEYNDRICKX, M.; DE VLIEGHER, S. Distribution of coagulasenegative Staphylococcus species from milk and environment of dairy cows differs between herds. Journal Dairy Science, v. 94, n. 6, p. 2933-2944, 2011

36. PINZÓN-SÁNCHEZ, C.; RUEGG, P. L. Risk factors associated with short-term posttreatment outcomes of clinical mastitis. Journal Dairy Science, v. 94, n. 7, p. 33973410, 2011.

37.PYÖRÄLÄ, S.; TAPONEN, S. Coagulase-negative staphylococci-emerging mastitis pathogens. Veterinary Microbiology, v. 134, n. 1-2, p. 3-8, 2009.

38. RENDOS, J. J.; EBERHART, R. J.; KESLER, E. M. Microbial populations of teat ends of dairy cows, and bedding materials. Journal Dairy Science, v. 5REYHER, K. K.; HAINE, D.; DOHOO, I. R.; REVIE, C. W. Examining the effect of intramammary infections with minor mastitis pathogens on the acquisition of new intramammary infections with major mastitis pathogens-A systematic review and meta-analysis. Journal Dairy Science, v. 95, n. 11, p. 6483-6502, 2012.

39. RUEGG, P. L. New perspectives in udder health management. Veterinary Clinics North America: food animal practice, v. 28, n. 2, p. 149-163, 2012

40. SAMPIMON, O. C.; BARKEMA, H. W.; BERENDS, I. M. G. A.; SOL, J.; LAM, T. J. G. $M$. Prevalence and herd-level risk factors for intramammary infection with coagulasenegative staphylococci in Dutch dairy herds. Veterinary Microbiology, v. 134, n. 1-2, p. $37-44,2009$

41. SAMPIMON, O.; VAN DEN BORNE, B. H. P.; SANTMAN-BERENDS, I.; BARKEMA, H W.; LAM, T. Effect of coagulase-negative staphylococci on somatic cell count in Dutch dairy herds. Journal Dairy Science, v. 77, n. 3, p. 318-324, 2010.

42. SANTOS, M. V.; FONSECA, L. F. L. Estratégias para controle de mastite e melhoria da qualidade do leite. São Paulo: Manole, 2006. 314 p.

43. SCHUKKEN, Y. H.; GONZÁLEZ, R. N.; TIKOFSKY, L. L.; SCHULTE, H. F.; SANTISTEBAN C. G.; WELCOME, F. L.; BENNETT, G. J.; ZURAKOWSKI, M. J.; ZADOKS, R. N. CNS mastitis: nothing to worry about? Veterinary Microbiology, v. 134, n. 1-2, p. 9-14, 2009.

44. SCHUKKEN, Y. H.; SMIT, J. A. H.; GROMMERS, F. J.; VANDEGEER, D.; BRAND, A Effect of freezing on bacteriologic culturing of mastitis milk samples. Journal Dairy Science, v. 72, n. 7, p. 1900-1906, 1989.

45.SCHUKKEN, Y.; CHUFF, M.; MORONI, P.; GURJAR, A.; SANTISTEBAN, C.; WELCOME, F.; ZADOKS, R. The "other" gram-negative bacteria in mastitis: klebsiella, serratia, and more. Veterinary Clinics North America: food animal practice, v. 28, n. 2, p. $239-256,2012$
46. SHARMA, N.; RHO, G. J.; HONG, Y. H.; KANG, T. Y.; LEE, H. K.; HUR, T. Y.; JEONG, D. K. Bovine mastitis: an Asian perspective. Asian Journal Animal Veterinary Advances, v. 7, n. 6 , p. $454-476,2012$.

47. SORDILLO, L. M.; DOYMAZ, M. Z.; OLIVER, S. P.; DERMODY, J. T. Leukocytic Infiltration of Bovine Mammary Parenchymal Tissue in Response to Corynebacterium bovis Colonization. Journal Dairy Science, v. 72, n. 4, p. 1045-1051, 1989.

48. SUPRÉ, K.; HAESEBROUCK, F.; ZADOKS, R. N.; VANEECHOUTTE, M.; PIEPERS, S.; DE VLIEGHER, S. Some coagulase-negative Staphylococcus species affect udder health more than others. Journal Dairy Science, v. 94, n. 5, p. 2329-2340, 2011.

49. TAPONEN, S.; JANTUNEN, A.; PYORALA, E.; PYORALA, S. Efficacy of targeted 5-day combined parenteral and intramammary treatment of clinical mastitis caused by penicillin-susceptible or penicillin-resistant Staphylococcus aureus. Acta Veterinaria Scandinavica, v. 44, n. 1-2, p. 53-62, 2003.

50.TAPONEN, S.; PYÖRÄLÄ, S. Coagulase-negative staphylococci as cause of bovine mastitis: not so different from Staphylococcus aureus? Veterinary Microbiology, v. 134, n. 1-2, p. 29-36, 2009.

51.THORBERG, B. M.; DANIELSSON-THAM, M. L.; EMANUELSON, U.; PERSSON WALLER, K. Bovine subclinical mastitis caused by different types of coagulasenegative staphylococci. Journal Dairy Science, v. 92, n. 10, p. 4962-4970, 2009.

52. TIMM, C. D.; BERMURDES, R. F.; LADEIRA, S. L.; CRUCIO, B. R.; MELLO, D. F. M. Manejo de la antisepsia post-ordeña en el control de la mastitis por Corynebacterium bovis. In: CONGRESO PANAMERICANO DE LA LECHE, 7., 2000, Havana. Anales... [S.I.]: FEPALE, 2000. 66 p.

53. TOMAZI, T. Produção e composição do leite de vacas com mastite subclínica causada por Staphylococcus coagulase negativa. 2013. 113 p. Dissertação (Mestrado em Ciências) - Faculdade de Medicina Veterinária e Zootecnia, Universidade de São Paulo, Pirassununga, 2013.

54. VICTÓRIA, C.; DA SILVA, A. V.; ELIAS, A. O.; LANGONI, H. Corynebacterium bovis e os padrões de contagem de células somáticas no Brasil. Arquivos de Ciências Veterinárias e Zoologia da UNIPAR, v. 8, n. 2, p. 161-64, 2005.

55.WAAGE, S.; SKEI, H. R.; RISE, J.; ROGDO, T.; SVILAND, S.; ODEGAARD, S. A. Outcome of clinical mastitis in dairy heifers assessed by reexamination of cases one month after treatment. Journal Dairy Science, v. 83, n. 1, p. 70-76, 2000.

56.WATTS, J. L.; LOWERY, D. E.; TEEL, J. F.; ROSSBACH, S. Identification of Corynebacterium bovis and other Coryneforms Isolated from Bovine Mammary Glands. Journal Dairy Science, v. 83, n. 10, p. 2373-2379, 2000.

57. WOODWARD, W. D.; BESSER, T. E.; WARD, A. C.; CORBEIL, L. B. In vitro growth inhibition of mastitis pathogens by bovine teat skin normal flora. Canadian Journal Veterinary Research, v. 51, n. 1, p. 27-31, 1987.

58.ZADOKS, R. N.; MIDDLETON, J. R.; MCDOUGALL, S.; KATHOLM, J.; SCHUKKEN $\mathrm{Y}$. H. Molecular epidemiology of mastitis pathogens of dairy cattle and comparative relevance to humans. Journal Mammary Gland Biology Neoplasia, v. 16, n. 4, p. 357-372, 2011

59.ZDANOWICZ, M.; SHELFORD, J. A.; TUCKER, C. B.; WEARY, D. M.; VON KEYSERLINGK, M. A. G. Bacterial populations on teat ends of dairy cows housed in free stalls and bedded with either sand or sawdust. Journal Dairy Science, v. 87, n. 6 , p. $1694-1701,2004$ 